\title{
STUDI KINERJA KENDALI DAYA KANAL UPLINK 4G LTE BERDASARKAN SIGNAL TO INTERFERENCE RATIO (SIR)
}

\author{
Sapta Nugraha ${ }^{1}$ dan Rozeff Pramana ${ }^{2}$ \\ ${ }^{1,2}$ Jurusan Teknik Elektro, Fakultas Teknik, Universitas Maritim Raja Ali Haji \\ Email: saptanugraha@umrah.ac.id
}

\begin{abstract}
$4 G$ Long Term Evolution (LTE) has a standard for wireless communication with high-speed data access on cellular phones which have standard parameter i.e. power control. Power control is a method to avoid interference inter-users, as a result of power variations. Interference inter-users will cause performance limitations of the quality of service telecommunications operator. In this paper, we will design power control on the uplink channel based on the Signal to Interference Ratio (SIR) so that power level of mobile station (MS) are approximately equal. Simulation results show that power of $M S$ can reach $-7 \mathrm{~dB}$, average time above $17 \mathrm{~ms}$. The results of the SIR can order MS to equalize the SIR power levels transmitted by some MS with SIR reference value.
\end{abstract}

Keywords: power control, uplink channel, SIR, mobile station

\begin{abstract}
ABSTRAK
4G Long Term Evolution (LTE) memiliki standar komunikasi nirkabel akses data berkecepatan tinggi pada telepon seluler yang memiliki parameter standar yaitu kendali daya. Kendali daya merupakan metode untuk menghindari interferensi antar pengguna akibat variasi daya. Interferensi antar pengguna menyebabkan keterbatasan kinerja kualitas layanan operator telekomunikasi. Pada penelitian ini, akan dirancang kendali daya kanal uplink berdasarkan SIR agar daya mobile station (MS) mendekati sama. Hasil simulasi menunjukkan bahwa daya MS dapat mencapai $-7 \mathrm{~dB}$, rerata waktu di atas $17 \mathrm{~ms}$. Hasil menunjukkan SIR dapat memerintahkan MS menyamakan daya yang ditransmisikan beberapa MS dengan nilai SIR referensi.
\end{abstract}

Kata Kunci: kendali daya, kanal uplink, SIR, mobile station

\section{PENDAHULUAN}

Long Term Evolution (LTE) merupakan pengembangan teknologi telekomunikasi dari 3G ke 4G. Kemampuan dan keunggulan dari LTE memiliki kecepatan dalam transfer data, cakupan area yang besar, serta memiliki kapasitas dan layanan yang lebih besar. Selain itu, penerapan penggunaan antena jamak, fleksibel dalam penggunaan bandwidth operasinya, dan terintegrasi dengan teknologi yang sudah ada dapat menekan biaya operasional yang lebih rendah (Suyuti dan Syarif, 2011; Usman dan Prihatmoko, 2011).

Peningkatan kapasitas dan layanan merupakan standar yang coba dikembangkan oleh teknologi LTE ini. Untuk meningkatkan kapasitas dan layanan diperlukan sistem pengaturan daya yang optimal antara Mobile Station (MS) dan eNodeB. Sistem pengaturan daya dapat mengurangi interferensi antar pengguna jaringan telekomunikasi. Interferensi adalah gangguan sinyal komunikasi yang disebabkan oleh ikut diterimanya sinyal frekuensi lain yang tidak dikehendaki. Interferensi ini menyebabkan penurunan kinerja sistem radio seluler, baik berupa kapasitas maupun layanan jaringan telekomunikasi.

LTE memerlukan suatu kendali daya untuk meminimalisasi terjadinya interferensi antar pengguna, sebagai akibat variasi daya yang akan menimbulkan korelasi silang. Korelasi silang adalah kode 
penebar transmisi pada kanal uplink dengan menggunakan kode acak. Kendali daya bekerja dengan cara mengatur daya pancar pengguna penginterferensi karena level interferensi yang tinggi dari sel tetangga dapat membatasi area cakupan uplink. Kendali daya uplink dapat meningkatkan kinerja cell-edge sehingga kapasitas sistem bekerja secara optimal. Selain itu, kendali daya uplink cukup efektif dalam mengurangi interferensi pada sistem LTEadvanced (Khan, 2009; Febryanti, Hendrantoro, dan Kuswidiastuti, 2013; Cîrstea dan Ciochină, 2011).

LTE menggunakan teknik Single Carrier Frequency Division Multiple Access (SC-FDMA) pada kanal uplink. Kendali daya memiliki dua mekanisme dalam proses mengurangi interferensi yang terjadi, yaitu Open Loop Power Control (OLPC) dan Closed Loop Power Control (CLPC). Pengujian sistem diterapkan dengan membandingkan antara kinerja OLPC dan CLPC menggunakan skema frekuensi reuse yang berbeda. Mekanisme kinerja CLPC memiliki sistem yang optimal dibandingkan dengan kinerja OLPC (Elbadawy, El-Ghawaby, dan Ali, 2012; Tejaswi dan Suresh, 2013)

Penelitian ini akan melakukan studi kinerja kendali daya agar level daya yang ditransmisikan dari setiap MS minimal mendekati sama. Hal ini diwujudkan dengan mengatur level daya yang ditransmisikan oleh MS menggunakan kendali daya loop tertutup pada kanal uplink melalui mekanisme algoritma Signal to Interference Ratio (SIR).

\section{METODE}

\section{Kriteria Perancangan}

Pada bagian ini akan dirancang mekanisme kendali daya menggunakan pendekatan algoritma SIR berdasarkan pada obyek yang berbeda. Algoritma SIR didasarkan pada obyek untuk secara langsung mengontrol kualitas komunikasi atau kinerja sistem sesuai dengan SIR yang diterima pada eNodeB.

Mekanisme kendali daya pada kanal uplink, jika $e N o d e B$ mengukur rerata daya dari SIR yang diterima pada reverse link (uplink) yang diinginkan dalam suatu periode pengukuran daya, dinyatakan dengan $\overline{S I R}$. Perbandingan $\overline{S I R}(\mathrm{~dB})$ dengan level daya yang diinginkan $D(\mathrm{~dB})$ disebut mekanisme kendali daya SIR. Dalam bahasan ini, $\overline{S I R}$ diperoleh dari :

$$
\overline{S I R}=\bar{B}-(I(t)+\mathrm{n}(\mathrm{t}))
$$

dengan $I(t)$ merupakan level interferensi dari semua mobile station yang lain dalam sistem. $\mathrm{n}(\mathrm{t})$ adalah background noise. eNodeB mengukur rerata daya sinyal yang diterima dalam suatu periode pengukuran daya yang dinyatakan dalam $\bar{B}$.

Perbedaan antara $\overline{S I R}(\mathrm{~dB})$ dan $D(\mathrm{~dB})$ dalam mekanisme SIR, dinyatakan dalam err, kemudian diumpankan ke dalam Power Control Decision Command (PCCMD). PCCMD ini akan mengirimkan sebuah perintah kendali daya ke mobile station via kanal umpan balik dari kanal downlink.

Aturan yang berhubungan untuk menentukan perintah kendali daya adalah jika nilai $k e y \geq 0$, maka nilai $\mathrm{cmd}=0$. Apabila nilai key $<0$, maka nilai $\mathrm{cmd}=1$, dengan $k e y=$ err $/$ $\Delta_{P}$ dan $\Delta_{P}$ merupakan step size minimum untuk proses penjajakan daya. Setelah menerima perintah kendali daya $(\mathrm{cmd})$, mobile station memancarkan daya yang diperbarui oleh sejumlah $c m d * \Delta_{P}(\mathrm{~dB})$.

Periode waktu yang diperlukan mobile station untuk melakukan satu operasi penjajakan disebut loop delay dan dinyatakan $T_{d}$. Loop delay meliputi periode pengukuran daya $\left(T_{P}\right)$, delay propagasi kanal uplink dan downlink, dan time delay untuk membangkitkan, mentransmisikan, dan mengeksekusi perintah kendali daya. Loop delay memainkan peranan yang penting dalam mekanisme kendali daya. 


\section{Pemodelan Sistem}

Perancangan pemodelan sistem kinerja kendali daya ini berdasarkan mekanisme closed loop kendali daya pada kanal uplink dengan metode fixed step. Diagram alir mekanisme pemodelan sistem dengan metode fixed step ini ditunjukkan pada gambar 1. Pemodelan ini menggunakan sistem dengan sel tunggal. Sel yang dimaksud diasumsikan bebas dari edge effect. MS dalam sel tersebut diasumsikan di dalam sel dengan kerapatan uniform dengan jumlah $N_{u}$ MS.
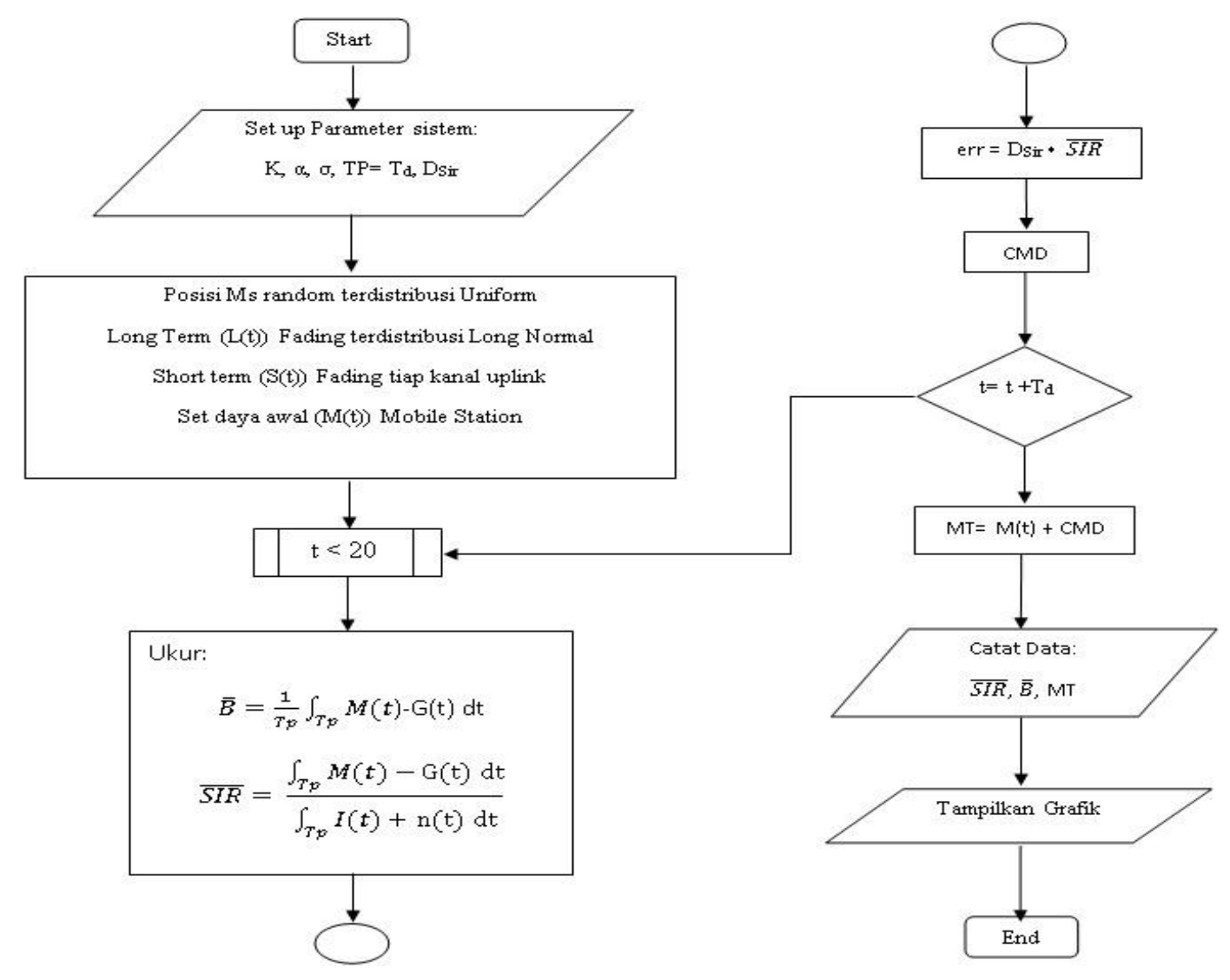

Gambar 1. Diagram Alir Pemodelan Sistem

Sinyal radio pada waktu t dalam kanal uplink dari pusat sel diasumsikan mengalami redaman oleh suatu channel gain $\mathrm{G}(\mathrm{t})$ yang meliputi long term fading dan short term fading. Long term fading dinyatakan oleh $\mathrm{L}(\mathrm{t})$ dan menggambarkan rerata dari daya sinyal. Short term fading dinyatakan oleh $\mathrm{S}(\mathrm{t})$ menjelaskan multipath fading. Oleh karena itu, diberikan daya yang ditransmisikan sebuah mobile station $\mathrm{M}(\mathrm{t})$, maka daya yang diterima eNodeB $\bar{B}$ dapat diperoleh dengan:

$\bar{B}(t)=M(t)+G(t)=M(t)+L(t)+S(t)$
Long term fading $L(t)$ merupakan suatu random variable yang dimodelkan sebagai berikut:

$$
L(t)=K \cdot r^{-\alpha} \cdot 10^{\xi / 10}
$$

dengan $K$ adalah suatu konstanta, $r$ merupakan jarak antara eNodeB dan mobile station, $\alpha$ dinamakan eksponen path rugi, dan $\xi$ adalah random variable terdistribusi normal dengan rerata nol dan variansi $\sigma$. Dalam simulasi ini digunakan $K=1, \alpha=4$ dan $\sigma=8$. Short term fading $S(t)$ yang digunakan pada simulasi ini juga merupakan random variable dengan distribusi Rayleigh. 
Pada periode pengamatan loop delay, setiap mobile station diasumsikan bergerak secara kontinyu dalam suatu area geografis yang kecil, sehingga kanal radio uplink mempunyai rugi redaman dan shadowing yang uniform. Oleh karena itu, long term fading pada tiap kanal uplink dapat dianggap konstan selama periode pengamatan. Antena yang digunakan oleh eNodeB dan mobile station dianggap omnidirectional. Aktivitas suara dan soft handoff tidak diperhitungkan dalam simulasi ini.

Microcell digunakan pada area dengan kepadatan yang tinggi, seperti pusat kota, jalan raya atau pusat bandar udara, dan memiliki ukuran sel yang kecil untuk mencapai kapasitas pengguna per unit area yang lebih tinggi. Ukuran microcell $(0.5 \mathrm{Km}$ sampai $2 \mathrm{Km})$ dan antena pada microcell juga bekerja dengan daya pancar yang relatif lebih kecil (kurang dari 20 $\mathrm{mW})$.

Level daya dari MS berdasarkan link budget untuk sistem LTE maksimum $200 \mathrm{~mW}$ atau $23 \mathrm{dBm}$. Berdasarkan parameter tersebut, simulasi ini diasumsikan yang mana MS bergerak secara random dalam area sel $0.5 \mathrm{Km}$ hingga $2 \mathrm{Km}$. Nilai level SIR referensi untuk simulasi yaitu -7 dB. Daya pancar MS diasumsikan 0,01 $\mathrm{mW}$ atau $-50 \mathrm{~dB}$.

Parameter LTE yang diinginkan pada simulasi ini dinyatakan dalam bit error rate adalah kurang dari $10^{-3}$ atau Eb/Io berkisar 4 5 untuk uplink. Data rate $64 \mathrm{Kbps}$ dan laju chips $(\mathrm{W})=4,096$ Mcps, sehingga processing gain $\mathrm{W} / \mathrm{R}=64$, maka minimum SIR yang diinginkan adalah sekitar $-7 \quad d B$. Tabel 1 menunjukkan parameter-parameter simulasi yang digunakan dalam perancangan sistem uplink kendali daya ini.
Tabel 1. Parameter Simulasi

\begin{tabular}{ll}
\hline Parameter & Nilai \\
\hline Data Rate (Kbps) & 64 \\
Chips Rate (Mcps) & 4.096 \\
Processing Gain & 64 \\
Frequency Carrier $(\mathrm{MHz})$ & 2100 \\
Max. Tx Power MS $(\mathrm{dBm})$ & 23 \\
SIR Referensi (dB) & -7 \\
Mobile Station $($ user $)$ & 10 \\
Eb/Io & 5 \\
& $0.5-$ \\
Jangkauan Microcell $(\mathrm{Km})$ & 2 \\
Daya Pancar Antena (mW) & $<20$ \\
Frequency Reuse & 1 \\
Gain Antenna Sektorisasi & 2.4 \\
Periode PC $=$ Tp (ms) & 0.2 \\
\hline
\end{tabular}

Pada bagian sebelumnya telah disebutkan bahwa, long term fading konstan untuk setiap pengguna dengan asumsi perpindahan MS relatif kecil. Sementara short term fading diasumsikan terdistribusi Rayleigh. Short term fading terdistribusi Rayleigh yang digunakan pada simulasi ini dapat dilihat pada gambar 2.

\section{Sebelum Kendali Daya dilakukan}

Hasil simulasi SIR yang ditransmisikan beberapa mobile station sebelum kendali daya sebesar -50 dB ditunjukkan gambar 3. Hasil simulasi menunjukkan bahwa level daya yang ditransmisikan beberapa mobile station sebelum kendali daya mendapatkan hasil yang sama yaitu sebesar $-50 \mathrm{~dB}$.

Hasil simulasi level daya yang diterima $e N o d e B$ sebelum menggunakan kendali daya ditunjukkan gambar 4 dengan nilai SIR referensi adalah -7 dB. Hasil simulasi menunjukkan bahwa level daya yang diterima eNodeB dari beberapa MS sebelum kendali daya terlihat berbeda dari SIR referensi. Hal ini disebabkan oleh faktor jarak (near-far) dan shadowing dari MS menuju eNodeB. Faktor jarak ini menentukan lokasi setiap MS berbeda dengan MS yang lainnya. Perbedaan lokasi 
ditentukan berdasarkan distribusi acak pada lokasi MS.

Selain itu, adanya interferensi antar MS juga mengakibatkan level daya yang diterima BS belum stabil. Perbedaan inilah yang coba akan dilakukan pengaturan level daya sehingga akan menyesuaikan dengan level daya target yang diinginkan menggunakan mekanisme kendali daya.

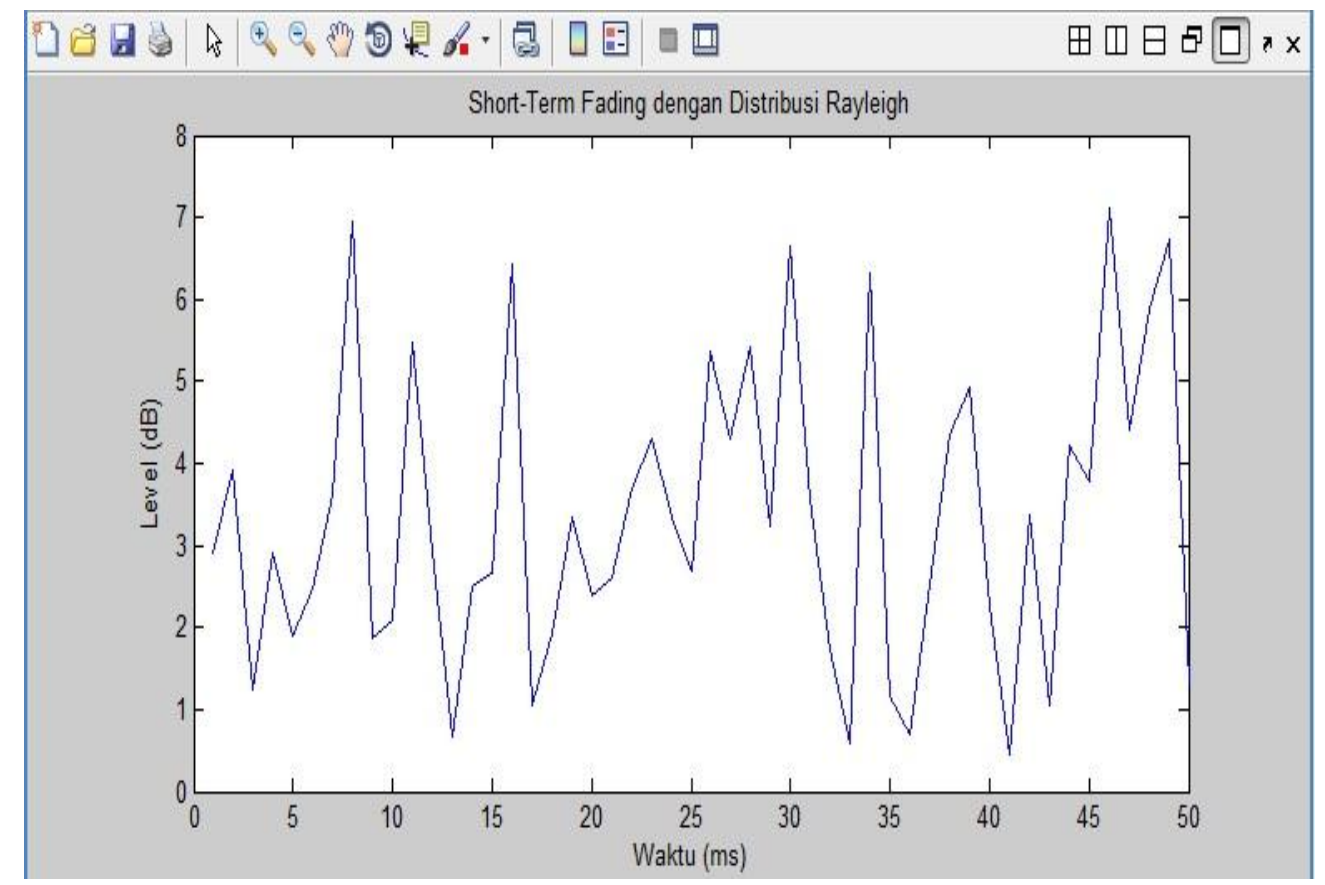

Gambar 2. Short Term Fading Terdistribusi Rayleigh

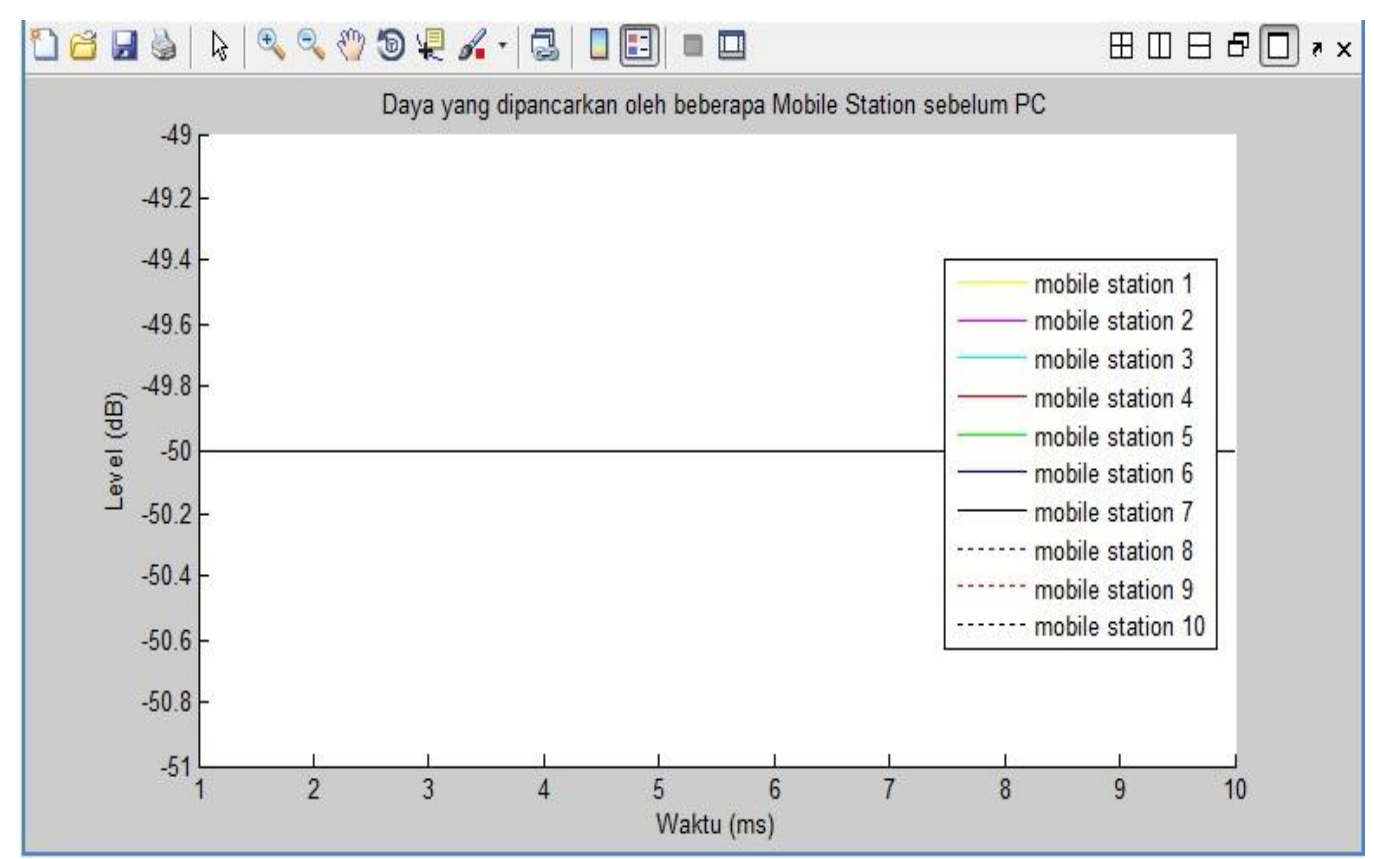

Gambar 3. Daya yang ditransmisikan Mobile Station Sebelum Kendali Daya 


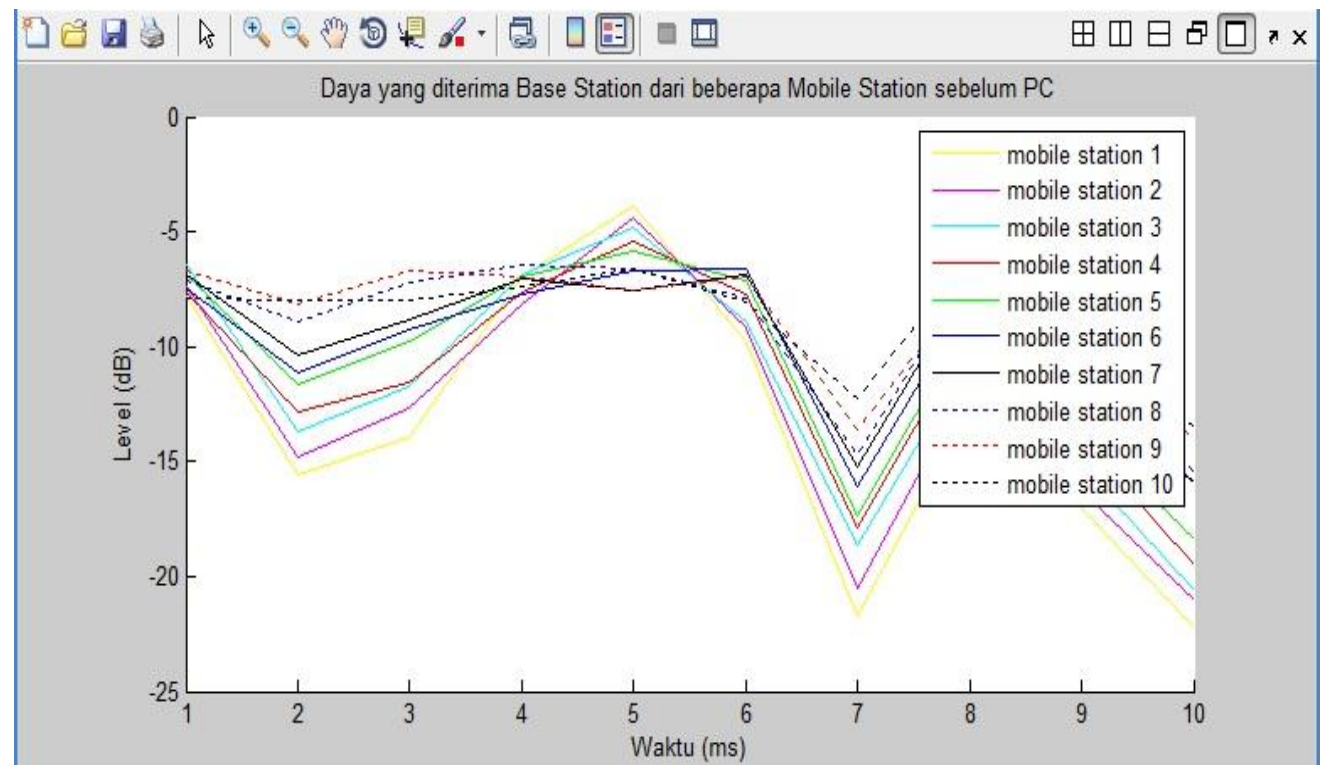

Gambar 4. Daya yang diterima $e N o d e B$ Sebelum Kendali Daya

\section{Setelah Kendali Daya dilakukan}

Hasil simulasi level daya yang ditransmisikan beberapa MS dengan menggunakan kendali daya sebesar $-50 \mathrm{~dB}$ ditunjukkan gambar 5. Hasil simulasi menunjukkan perubahan daya pancar beberapa MS akibat adanya penggunaan kendali daya. Daya pancar MS pada simulasi ini akan terus mengalami perubahan selama proses komunikasi akibat adanya pergerakan dan multipath fading yang dialami oleh MS.

Hasil simulasi level daya yang diterima eNodeB dari beberapa MS setelah menggunakan kendali daya ditunjukkan gambar
6. Hasil simulasi menunjukkan bahwa SIR mencapai level daya $-7 \mathrm{~dB}$ dengan waktu ratarata di atas $17 \mathrm{~ms}$. Hal ini menunjukkan bahwa kendali daya dapat melakukan tugasnya dengan baik yaitu memerintahkan MS untuk menyamakan level daya SIR yang ditransmisikan oleh beberapa MS dengan nilai SIR referensi.

Pada algoritma SIR, nilai fluktuasi level daya $-7 \mathrm{~dB}$ dengan waktu sampling terdekat (MS 1) adalah $1 \mathrm{~ms}$ dan waktu sampling terjauh (MS 10) adalah $17 \mathrm{~ms}$. Waktu sampling ini terjadi berdasarkan pada perubahan kendali daya.

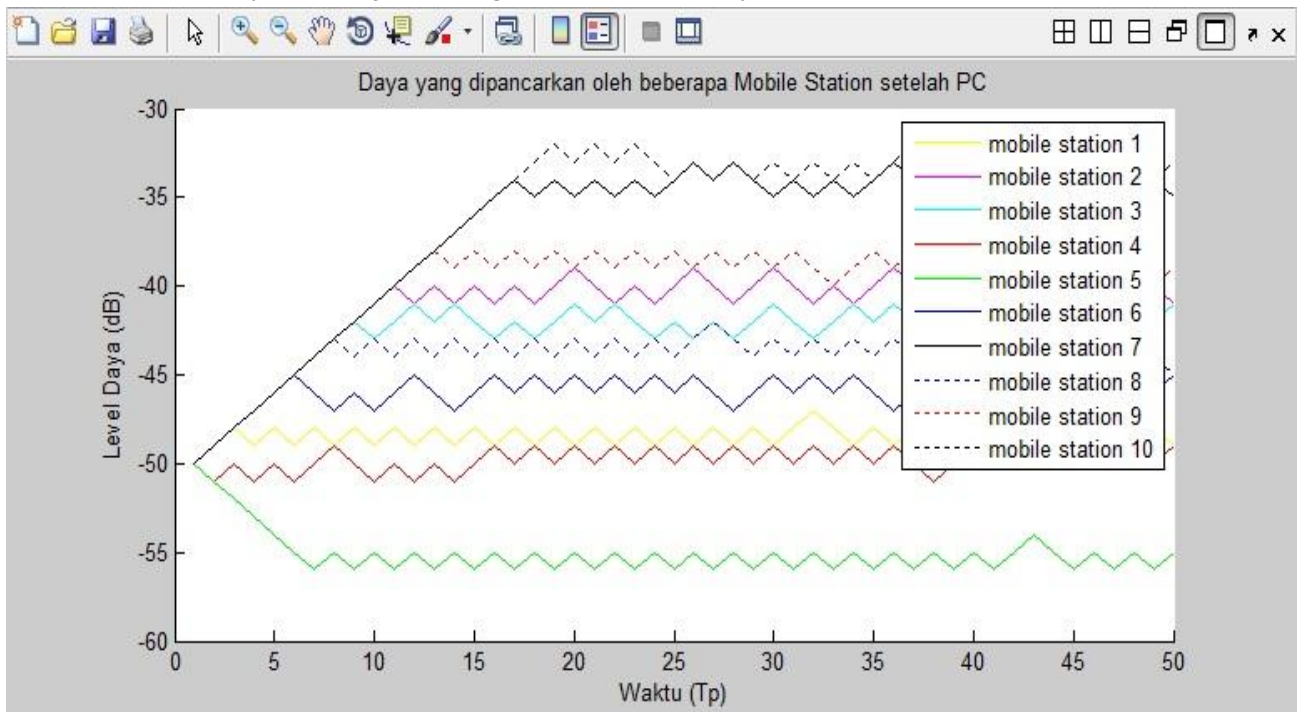

Gambar 5. Daya yang ditransmisikan Mobile Station Setelah Kendali Daya 


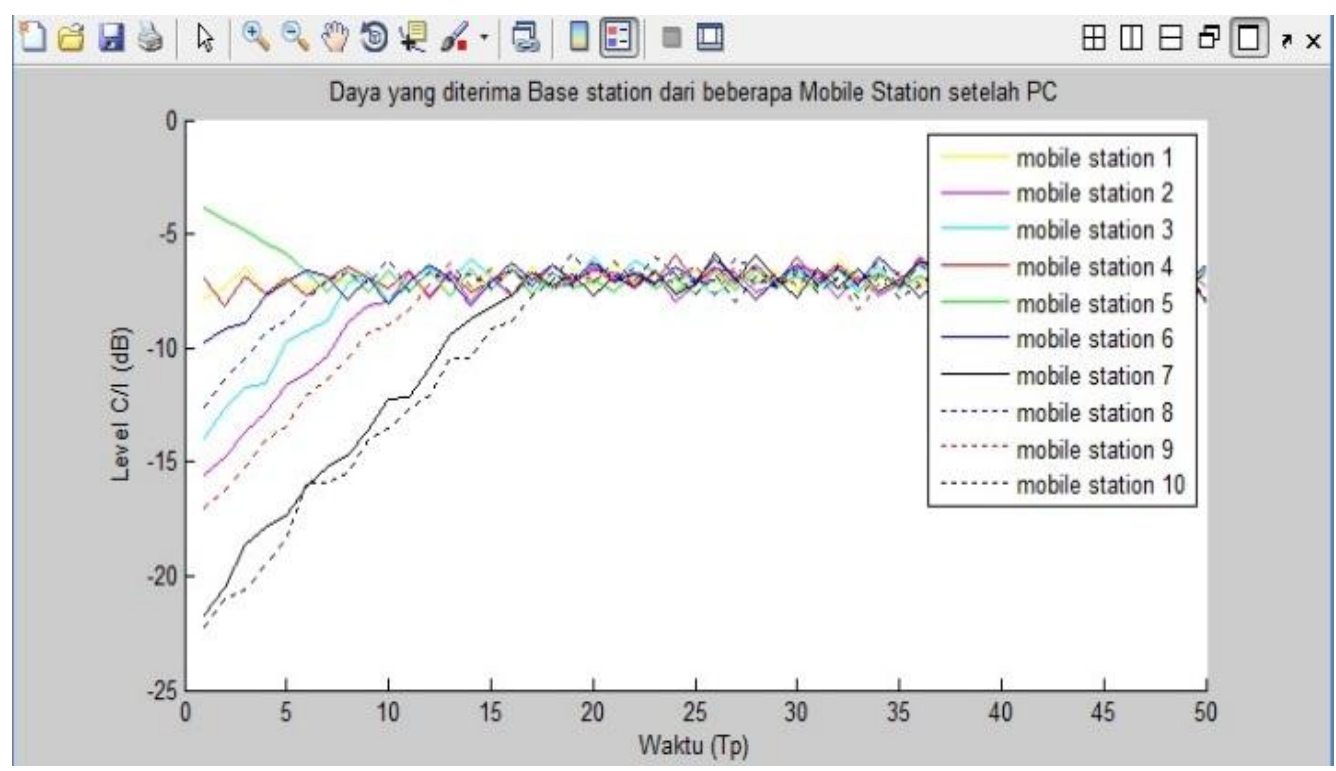

Gambar 6. Daya yang diterima eNodeB Setelah Kendali Daya

\section{SIMPULAN}

Algoritma SIR merupakan salah satu algoritma yang optimal digunakan dalam teknik uplink kendali daya. Hasil menunjukkan bahwa SIR mencapai level daya $-7 \mathrm{~dB}$ dengan waktu rata-rata di atas $17 \mathrm{~ms}$. Hal ini menunjukkan bahwa kendali daya dapat memerintahkan MS untuk menyamakan level daya SIR yang ditransmisikan oleh beberapa MS dengan nilai SIR referensi.

\section{DAFTAR RUJUKAN}

Cîrstea, E.-R., \& Ciochină, S. 2011. Adaptive, $3^{\text {rd }}$ International Conference on Adaptive and Self-Adaptive Systems and Applications.

El-badawy, H., El-Ghawaby, M. M., \& Ali, H. H. 2012. The Seventh International
Conference on

Telecommunications,

Febryanti, S., Hendrantoro, G., \& Kuswidiastuti, D. 2013. Jurnal Teknik Pomits.

Khan, F. 2009. LTE for $4 G$ Mobile Broadband. Air Interface Technologies and Performance. United Kingdom: Cambridge University Press.

Suyuti, S., \& Syarif, S. 2011. Jurnal Ilmiah Elektrikal Enjiniring UNHAS.

Tejaswi, E., and Suresh, B. 2013. Int. J. Comput. Sci. Inf. Technol.

Usman, K., \& Prihatmoko, G. U. 2011. Fundamental Teknologi Seluler LTE. Bandung: Informatika. 